Original Research Article

\title{
Drug price control order: the impact on pharmacoeconomics
}

\author{
Suchi M. Shah ${ }^{1}$, Anil P. Singh ${ }^{2}$, Parth K. Vachhani ${ }^{3}$
}

${ }^{1}$ Department of Pharmacology,

BJ Medical College, Asarwa, Ahmedabad, Gujarat, India

${ }^{2}$ Department of Pharmacology,

Pandit Deendayal Upadhyay

Government Medical College,

Rajkot, Gujarat, India

${ }^{3}$ Global Pharmacovigilance, Apotex Research Private Limited, Mumbai, Maharashtra, India

Received: 18 June 2019

Revised: 13 August 2019

Accepted: 11 September 2019

*Correspondence to:

Dr. Suchi M. Shah,

Email: suchi.shah1990

@gmail.com

Copyright: (C) the author(s), publisher and licensee Medip Academy. This is an openaccess article distributed under the terms of the Creative Commons Attribution NonCommercial License, which permits unrestricted noncommercial use, distribution, and reproduction in any medium, provided the original work is properly cited.

\begin{abstract}
Background: The objective of the present study was to analyze the prices of metformin, losartan, atorvastatin, paracetamol and aspirin for the doses which are included in the list of Drug Price Control Order (DPCO) 2013.

Methods: Current index medical specialties India, 37th year, April-July 2015 issue was used for analysis. The retail prices of the drugs in INR were tabulated in Microsoft Office Excel 2013. The prices of the above listed drugs were compared with prices of DPCO 2013 for the same doses of drugs. The analysis of drugs costing more than the prices listed in the DPCO with the margin of the difference in percentage was carried out.

Results: Out of 25 brands of metformin $500 \mathrm{mg}$ tablet, 11 (44\%) brands had price higher than listed in DPCO 2013. Similarly, prices for losartan $25 \mathrm{mg}$ and $50 \mathrm{mg}$ tablets, $8(25 \%)$ out of 32 and $11(31.42 \%)$ out of 35 were higher respectively. For atorvastatin $5 \mathrm{mg}$ and $10 \mathrm{mg}$ tablets, $2(9.52 \%)$ out of 21 and 8 $(13.55 \%)$ out of 59 brands had higher prices. For paracetamol $500 \mathrm{mg}$ tablet, 12 (63.15\%) out of 19 brands were priced higher than DPCO list. For aspirin 100 mg tablet and $325 \mathrm{mg}$ tablet, 3 (100\%) out of 3 brands and 1 (100\%) out of 1 brand had higher prices.

Conclusions: Many of the brand formulations have higher prices than the DPCO 2013 issued by government of India. The clinicians prescribing these drugs should be aware of these brand formulations to reduce the cost of the drug therapy.
\end{abstract}

Keywords: Drug price control order, Price variation, Pharmacoeconomics, Compliance

\section{INTRODUCTION}

Indian pharmaceutical market is predominantly a branded market: more than one company sells a particular drug under different brand names apart from the innovator company. India is emerging as a fast-growing pharmaceutical market in the globe. The Indian pharmaceutical sector was valued at US\$ 33 billion in 2017 and the country's pharmaceutical industry is expected to expand at a Compound annual growth rate of 22.4 per cent over 2015-20 to reach US $\$ 55$ billion. ${ }^{1}$ But, there are major differences between Maximum retail price (MRPs) among various branded formulations of the same drug in the market which can lead to increased economic burden on patient and the country and that can influence patient compliance.

Pharmacoeconomics has been defined as the description and analysis of the cost of the drug therapy to health care system and society. It identifies, measures and compare the costs (resources consumed) and consequences (i.e., clinical, economic, and humanistic) of pharmaceutical products and services. It is an essential tool for resource allocation and decision making in various pharmaceutical sectors, including drug pricing. ${ }^{2}$ 
Drug price control order (DPCO) 2013 aims at making all essential and lifesaving medicines available to all at affordable prices through the instrumentality of price control. Under the Defense of India Act 1963, the first price control order was issued. After that, price control order has been issued under Essential Commodities Act 1970 and has been revised in 1979, 1987, 1995 and 2013.

DPCO 2013 was issued by the Ministry of Chemicals and Fertilizers for fixing the ceiling prices of 348 drugs included in National List of Essential Medicine 2011, by the independent body- National pharmaceutical pricing authority (NPPA). Drug prices are monitored and controlled by NPPA by adopting National pharmaceutical pricing policy (NPPP) which is based on the approach of Market-based pricing (MBP) for price fixation of drugs. NPPP is structured around 3 key principles of drug essentiality, MBP and control of formulations only. MBP is calculated by adding the average of the prices of all the brands of a drug having at-least $1 \%$ market share plus local taxes and a $16 \%$ retailer's profit margin. ${ }^{3}$ Violation of the DPCO can lead to notice period of 45 days to the manufacturer, within which drug price modification should be done and the overcharged amount with interest and the penalty has to be submitted to the government. ${ }^{4}$

This study compares prices of various branded formulations used most frequently in clinical practice, with their fixed ceiling prices given in the DPCO 2013 and assesses the compliance of DPCO along with the impact of it on Indian pharmacoeconomics.

\section{METHODS}

The drugs metformin $500 \mathrm{mg}$, losartan $25 \mathrm{mg}$ and $50 \mathrm{mg}$, atorvastatin $5 \mathrm{mg}$ and $10 \mathrm{mg}$, aspirin $100 \mathrm{mg}$ and $325 \mathrm{mg}$ and paracetamol $500 \mathrm{mg}$ were included in the analysis. The prices of various brands of above-mentioned drugs available in the market were taken from Current index medical specialties (CIMS) India, $37^{\text {th }}$ year, April-July 2015 issue for the analysis. The retail prices of the drugs of various brands with the same doses in INR were tabulated in Microsoft Office Excel 2013.

The prices of the all the brands of above listed drugs from CIMS were compared with prices of the same doses of drugs from DPCO 2013. The analysis of drugs costing more than the prices listed in the DPCO was carried out with calculation of the percentage difference. Only oral formulations of above-mentioned drugs were included. No fixed dose combinations were included.

\section{RESULTS}

The study results show variation between MRP and DPCO capped price of included drugs; maximum with aspirin $100 \mathrm{mg}$ and $325 \mathrm{mg}(100 \%)$, minimum with atorvastatin $5 \mathrm{mg}(9.25 \%)$. For metformin $500 \mathrm{mg}$ tablet, $11(44 \%)$ brands, losartan $25 \mathrm{mg}$ and $50 \mathrm{mg}$ tablets, 8 $(25 \%)$ and $11(31.42 \%)$ brands respectively, atorvastatin $10 \mathrm{mg}$ tablets, $8(13.55 \%)$ brands, paracetamol $500 \mathrm{mg}$ tablet, $12(63.15 \%)$ brands had price higher than listed in DPCO 2013 (Table 1 and Figure 1).

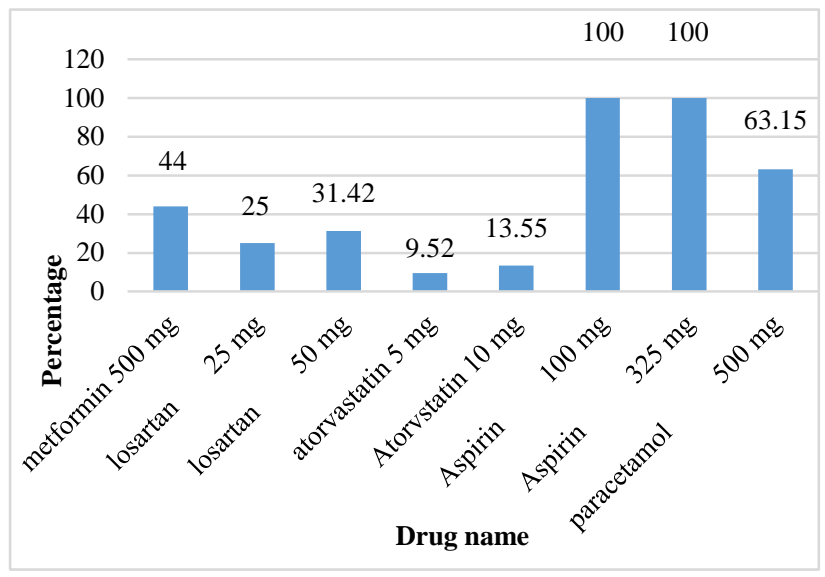

Figure 1: Percentage of drugs having higher prices than DPCO 2013.

Table 1: Comparison between various branded formulations of included drugs in CIMS (April-July 2015 issue) with DPCO 2013 prices.

\begin{tabular}{|llllll|}
\hline S. no. & Name of the drug & $\begin{array}{l}\text { Dose } \\
(\mathbf{m g})\end{array}$ & $\begin{array}{l}\text { No. of brands of the } \\
\text { drug available in the } \\
\text { market. According } \\
\text { to CIMS-July-2015 }\end{array}$ & $\begin{array}{l}\text { No. of brands with } \\
\text { prices higher } \\
\text { compared to DPCO }\end{array}$ & $\begin{array}{l}\text { Capped price for the } \\
\text { given drug according } \\
\text { to DPCO 2013 } \\
\text { (Rs/tablet) }\end{array}$ \\
\hline $\mathbf{1}$ & Metformin & 500 & 25 & 11 & 1.66 \\
\hline $\mathbf{2}$ & Losartan & 25 & 32 & 8 & 2.66 \\
\hline $\mathbf{3}$ & Losartan & 50 & 35 & 11 & 4.57 \\
\hline $\mathbf{4}$ & Atorvastatin & 5 & 21 & 2 & 4.06 \\
\hline $\mathbf{5}$ & Atorvastatin & 10 & 59 & 3 & 6.28 \\
\hline $\mathbf{6}$ & Aspirin & 100 & 3 & 1 & 0.40 \\
\hline $\mathbf{7}$ & Aspirin & 325 & 1 & 12 & 0.44 \\
\hline $\mathbf{8}$ & Paracetamol & 500 & 19 & & 1 \\
\hline
\end{tabular}




\section{DISCUSSION}

Paracetamol is ranked $1^{\text {st }}$, atorvastatin $7^{\text {th }}$, aspirin $8^{\text {th }}$ and metformin $13^{\text {th }}$ among top 20 generic molecules used world-wide. ${ }^{5}$ Also, the drugs mentioned above are listed in NEML 2011 and DPCO and are being used in clinical practice routinely. The data of the various branded formulations are taken from Current index medical specialties (CIMS) INDIA because of its regular updation and easy availability. ${ }^{6}$ The results of this study show variations in the MRP of branded formulations of various drugs listed in the DPCO 2013. Similar results were seen with the study done by Kumar et al in which only $60 \%$ of the anti-hypertensive drugs were found to have price according to the DPCO price list. ${ }^{4}$

The proposed reasons for basic price variations among marketed formulations can be lenient government regulations and pricing policies, the economic goals of the parent company, target return on investment, total expenditure of production, distribution and drug promotion, existing composition of the pharmaceutical

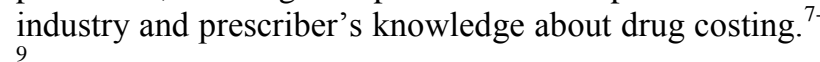

Wide variations of MRP of drugs in marketed formulations from DPCO indicate non-compliance of DPCO and increased economic burden on patients, society and health care system. Another study of costanalysis of DPCO showed drug price variations ranging from more than $100 \%$ from average to more than $500 \%$ between maximum and minimum brand prices. ${ }^{10}$

Violation of price notification issued by NPPA, depending upon the gravity of the offence, could attract prosecution under the section 7,9 and 10 of Essential Commodities Act, 1955. Punishment for violating the DPCO order may be imprisonment from 3 months to seven years as well as financial recovery of overcharging amount along with interest as arrears to land revenue under the Public Demand Recovery Act.4. ${ }^{4}$

In India, patient has to pay the medical bills out of his pocket directly as most of the people in India are not covered under medical insurance schemes. So, prescribing physicians can play a vital role in the pharmacoeconomics of the nation by prescribing the drug brands which have prices same or less than that mentioned in the DPCO. Prescription of generic drugs can help in selection of better priced drugs amongst the available branded formulations. The basic concepts like rational drug prescribing, $\mathrm{p}$-drug selection and generic prescribing should be taught thoroughly from undergraduate medical school for better prescribing practices and to minimize the cost of the drug therapy. ${ }^{11}$

Too stringent laws for price control can lead to manufacturers ceasing production of certain drugs with limited profit margin. Less profit may hamper research and development for new molecules in the pharmaceutical industry due decreased profit margins. The manufacturer may get influenced for production of doses of drugs which are not under price control e.g., paracetamol $650 \mathrm{mg}$ (price capped dose of paracetamol is $500 \mathrm{mg}$ ) and fixed dose combinations. Here, there is a need to strike a balance of profits, and affordability and availability of drugs as well as continued vigilance of DPCO compliance by the regulatory authority is also required.

\section{CONCLUSION}

Many of the brand formulations have higher prices than the DPCO 2013 issued by government of India. The clinicians prescribing these drugs should be aware of these brand formulations prices to reduce the cost of the drug therapy and increase patient compliance. Strict vigilance from the Government and more awareness from prescribers and patients are required. Better guidelines for regulatory implementation of DPCO is needed.

\section{Funding: No funding sources}

Conflict of interest: None declared

Ethical approval: The study was approved by the Institutional Ethics Committee

\section{REFERENCES}

1. Indian Pharmaceutical Industry. Available at: https:// www.ibef.org/industry/indian-pharmaceuticalsindustry-analysis-presentation. Accessed on 12 April 2019.

2. Maiti R. Pharmacoeconomics. Postgraduate topics in pharmacology. 1st ed. India: Paras Medical Books Pvt. Ltd; 2013; 203.

3. Kumar B, Medhi B. Drug Price. In: Medhi B, Prakash A, eds. Advanced pharmacology. Hyderabad: PharmaMed Press; 2014: 138-154.

4. Kumar R, Kumar N, Ahmad A, Kumar M, Rajendra $\mathrm{N}$, Dixit RK, et al. Cost comparison of antihypertensive drugs available in India with Drugs Prices Control Order price list. Int J Res Med Sci. 2019;7:101-5.

5. Top 20 generic molecules worldwide. Available at: http://www.fiercepharma.com/special-reports/top-20generic-molecules-worldwide. Accessed on 12 April 2019.

6. Current index medical specialties (CIMS) India, 37th year, April-July 2015 issue.

7. Sarkar PK. A rational drug policy. Indian J Med Ethics. 2004;12:30-5.

8. Roy V, Rewari S. Ambiguous drug pricing: a physician's dilemma. Indian J Pharmacol. 1998;30(6):404-7.

9. Berki SE, Richards JW, Weeks HA. The mysteries of prescription pricing in retail pharmacies. Med Care. 1977;15(3):241-50.

10. Atal S, Deshmankar B, Atal S, Nawaz SA. Cost analysis of commonly used drugs under price control in India: Assessing the effect of drug price control 
order on brand price variation. Int J Pharm Sci. 2016;8(4):315-21.

11. Tripathi KD. Aspects of pharmacotherapy, clinical pharmacology and drug development. Essentials of medical pharmacology, 7th ed. Delhi: Jaypee Brothers Medical Publisher (P) Ltd. Inc.; 2013: 7173.
Cite this article as: Shah SM, Singh AP, Vachhani PK. Drug price control order: the impact on pharmacoeconomics. Int J Basic Clin Pharmacol 2019;8:2220-3. 